\title{
Validation of the Batería III Woodcock-Munoz Pruebas de Habilidades Cognitivas for assessment of cognitive ability among children living in the Peruvian Amazon
}

\author{
Aaron Reuben, MEM, ${ }^{1}$ Helena Frischtak, ${ }^{2}$ MD, Rick Hoyle, PhD,${ }^{1}$ Pooja Mehta, BS, ${ }^{3}$ \\ Jasmin Wertz, PhD, ${ }^{1}$ Paige Bullins, BA, ${ }^{3}$ Ernesto Ortiz, MD, ${ }^{3}$ \\ Axel Berky, MEM, ${ }^{4}$ Ana Maria Morales, MD,${ }^{5} \&$ Laura L. Pendergast, $\mathrm{PhD},{ }^{6}$ \\ \& William Pan, DrPH MS MPH,,$^{3,4}$ \\ ${ }^{1}$ Department of Psychology and Neuroscience, Duke University, Durham, NC, USA \\ ${ }^{2}$ Contra Costa Regional Medical Center, Martinez, CA, USA \\ ${ }^{3}$ Global Health Institute, Duke University, Durham, NC, USA \\ ${ }^{4}$ Nicholas School of the Environment Duke University, Durham, NC, USA \\ ${ }^{5}$ Centro de Estudios, Investigaciones y Servicios en Salud Publica (CENSAP), Puerto Maldonado, Madre de Dios, \\ PERU \\ ${ }^{6}$ Department of Psychological Studies in Education, Temple University, Philadelphia, PA, USA
}

Correspondence should be addressed to:

Aaron Reuben, Duke University, aaron.reuben@duke.edu 


\section{Acknowledgements}

The authors would like to acknowledge the aid of the healthcare posts and the field technicians who assisted this study in each of the assessed communities. The authors would also like to thank Minerva Cartagena for her invaluable assistance. Special thanks to the children and families who participated in this study.

\section{Funding}

Funding for this study was provided by Hunt Oil Peru LLC to Duke University (HOEP-

QEHSS-140003, WP). The funders had no role in study design, data collection and analysis, interpretation, decision to publish, or preparation of the manuscript. HF received support as trainee, under the mentorship of WP, from the Doris Duke Foundation. AR was supported by the US-National Institute of Environmental Health Sciences grant F31ES029358. WP acknowledges additional support from Bass Connections and the Center for Latin American Studies at Duke University, the US-National Aeronautics and Space Administration (NNX15AP74G), and the US-National Institute of Environmental Health Sciences (R21ES026960). 


\begin{abstract}
This study examined the structural validity of scores from the Batería III WoodcockMunoz Pruebas de Habilidades Cognitivas (Batería III COG), the Spanish-language version of the Woodcock-Johnson III Tests of Cognitive Abilities (WJ III COG) among 164 children ages 5-12 living in the Peruvian Amazon. Exploratory factor analyses were used in the preliminary investigations. Subsequently, confirmatory factor analysis was utilized in the main analysis. The findings supported both a 4-correlated-factors structure, involving the cognitive domains of Verbal Comprehension, Working Memory, Processing Speed, and Fluid Reasoning, and a bi-factor structure, involving the cognitive domains of Verbal Comprehension, Working Memory, and Processing Speed and one General Intellectual Ability (GIA) factor. Findings from the bi-factor model support the use of the Batería III COG as a measure of GIA in this region but not necessarily as a measure of all hypothesized cognitive subdomains, which were largely subsumed into the GIA factor. Results confirm previous findings that $g$ predominates in the factor structure of scores produced by WJ III COG tests. Further implications for use of the Batería III COG in the Amazon region are discussed.
\end{abstract}




\section{The Batería III COG in the Peruvian Amazon}

\section{Overview of the study}

Children living in rural areas in developing countries face a number of obstacles to achieving their expected level of cognitive development, including malnutrition, low access to early learning opportunities, exposure to enteric pathogens and environmental pollutants, and maltreatment (Grantham-McGregor et al., 2007; Walker et al., 2007). Despite these potential threats, few studies of child cognitive development have examined outcomes among children living in rural communities in developing countries. In particular, there is a continuing need, globally, for locally validated instruments for assessing child cognitive development in these communities, as such tools are necessary before threats to healthy development can be identified, and, further, children at risk of delays targeted for intervention (Grantham-McGregor et al., 2007).

Children living in the Peruvian Amazon may be at particular risk of developmental delay, as many suffer from malnutrition, have low access to quality schooling, and experience high exposures to neurotoxic metal mixtures (e.g., methylmercury, cadmium, lead) owing to the growth of the small-scale mining sector (Diringer et al., 2015; Feingold \& Mulanovic, 2014; Weinhouse et al., 2017). However, accurate assessment of children's cognitive development outcomes in the Peruvian Amazon are currently hindered by a lack of cognitive assessment instruments validated for use in the region, which is ethnically, culturally, and linguistically distinct from other parts of the country (Blumen, 2016). In Peru, the most commonly used child cognitive tests, including the Wechsler Intelligence Scales for Children-Fourth Edition (WISC-IV), the Kaufman Assessment Battery for Children (K-ABC), and the Woodcock-Johnson 
Tests of Cognitive Abilities III (WJ III COG), utilize US norms and have received little empirical testing in Peru outside of Lima, the capital city. Further, while gross psychomotor screening tests, such as the Test Escala de Evaluacion del Desarrollo Psicomotor, are in use across the region, these tests only evaluate children up to age 5. To the best of our knowledge there are currently no fine-grained measures of cognitive ability validated for use with school-age children living in the Peruvian Amazon. This hinders, among other things, the identification of children with subtle learning disabilities and developmental delays.

In light of the unique risks facing children living in the Peruvian Amazon and the need for further validation of cognitive tests, this study examined the structure of scores from the Batería III Woodcock-Munoz Pruebas de Habilidades Cognitivas (Batería III COG) (Mather et al., 2008), the Spanish language version of the WJ III COG (Woodcock, McGrew, \& Mather, 2001), among 164 children aged 5 to 12 years living in 14 (indigenous and non-indigenous) communities in the Amazon Basin region. The goal was to determine whether the Batería III COG may be a valid tool for assessing cognitive ability among children living in the region and, if necessary, alter the tool to improve its validity for use in this population.

\section{Demographic and geographic context}

Peru (population 31.5 million) is an "upper middle income" developing country (United Nations, 2017) that has lately experienced high average economic growth (around 6\% annually) with a fast-expanding industrial sector, led by mining and manufacturing. Peru has 25 administrative regions loosely grouped into the Coast (11\% of the land, $52 \%$ of the population), the Highlands (30\% of the land, $36 \%$ of the 
population), and the Amazon (59\% of the land, $12 \%$ of the population) (The World Bank, 2018). The Peruvian population is nearly half indigenous (45\%), with most native people living in the Andean and Amazon regions (over 90\%). Indigenous communities have been traditionally the poorest and most vulnerable segments of Peruvian society (Hall, 2005). Inhabitants of native communities (excluding the non-contacted) are often bilingual, speaking both Spanish and an indigenous tongue. While Spanish is the official language in Peru, over forty languages are spoken in the Amazon region, with 120 recognizable local varieties (Cerron-Palomino, 2009).

This study focused on communities located in the southeastern Peruvian Amazon surrounding the Amarakaeri Communal Reserve in the region of Madre de Dios, considered one of the "hottest hotspots of biodiversity" (Myers, Mittermeier, Mittermeier, da Fonseca, \& Kent, 2000). 32 indigenous (ethno-linguistic native) communities are present in Madre de Dios, as well as several non-contacted tribes living in the region (Native Federation of the Madre de Dios River and Tributaries, 2014). The region is currently undergoing newly enhanced development owing to construction of the Interoceanic Highway and the expansion of artisanal and small-scale gold mining (Oliveira et al., 2007; Perz et al., 2008), which has contributed to mercury contamination in the region (Ashe, 2012; Wyatt et al., 2017).

\section{Cross-Cultural Assessment of Cognitive Ability}

Cognitive tests have been translated or adapted for use in Peru since at least the 1940’s (Blumen, 2016). Peru nevertheless still lacks valid and reliable fine-grained measures of child cognitive development in the hard-to-access and impoverished communities living in the Andean and Amazon regions (Blumen, 2016). Critically, tests 
developed and normed in one population can produce systematic estimation errors when used in another owing to, among other things, the use of inappropriate test content, inappropriate standardization samples, and unaccounted-for language differences among testers and test-takers (Reynolds \& Suzuki, 2013). As child cognitive tests can be used at the country level to inform public policy (e.g., the deployment of additional resources to high-need children or communities), the school level to inform teaching practice (e.g., aligning lesson content to child ability level), and the child level to identify learning disabilities or the need for special services, it is critical that cognitive tests measure what they intend to and do not, by merit of uncorrected biases, perpetuate discrimination, disenfranchisement, or cultural injustice. Evidence from the current study will assist in identifying whether in the Peruvian Amazon the Batería III COG measures the constructs it intends to and, additionally, whether any individual test items or tests may be potentially inappropriate for use with children living in this region.

\section{The Batería III Woodcock-Munoz Pruebas de Habilidades Cognitivas (Batería III COG)}

The Batería III COG contains 20 subtests measuring general intellectual ability, broad and narrow cognitive abilities, and aspects of executive functioning. The Batería III subtests were translated or adapted from the English WJ III COG by professionally certificated Spanish translators and native speakers. Test item difficulty was calibrated on 1,413 subjects who were native Spanish speakers living in Mexico, the United States, Costa Rica, Panama, Argentina, Columbia, Puerto Rico, and Spain. The Batería III COG yields a General Intellectual Ability (GIA) score using either the standard scale (tests 110), the extended scale (tests 11-20), or the brief scale, which uses a subset of tests from 
the standard and extended scales.

The theoretical foundation of the Batería III is the Cattell-Horn-Carroll theory of cognitive abilities (CHC theory) that broadly groups cognitive abilities into a general factor of ability $(g)$ that is comprised of more specific, narrowly defined abilities such as fluid reasoning $(G f)$, comprehension-knowledge $(G c)$, processing speed $(G s)$, and shortterm working memory (Gsm), among others (Schrank et al., 2005). The Batería III technical manual describes the full suite of tested subdomains of cognitive ability (Schrank et al., 2005).

While few cognitive tests have been validated for use with children in rural Peru, the Batería III COG is a particularly ideal test for assessments in the Amazon region because: 1) it measures performance across a wide variety of specific cognitive subdomains while also providing a measure of global, general cognitive ability, and 2) requires less training and less time to administer than similar fine-grained alternatives that measure cognitive ability both broadly and generally, such as the WISC-IV. The Batería III COG can be administered by any individual with a Bachelor's degree in an educational field, and, depending on how many subtests are selected, it can be fully administered within one to two hours.

\section{Psychometric research on the Batería III COG.}

Confirmatory factor analysis (CFA) was used in the WJ III development, producing a 9-factor model across all age ranges using the full battery (McGrew \& Woodcock, 2001). According to the technical manual, these 9 factors align with nine broad CHC cognitive domains (e.g., Crystallized Ability / Comprehension-Knowledge 
$[G c]$, Long-Term Retrieval [Glr], Visual-Spatial Thinking [Gv], Auditory Processing $[G a]$, Fluid Reasoning [Gf], Processing Speed $[G s]$, Reading-Writing Ability $[G r w]$, and Quantitative Reasoning $[G q])$. CFA of the Bateria III score structure among standardization samples in Mexico, the United States, Costa Rica, Panama, Argentina, Colombia, Peurto Rico, and Spain confirmed the 9-factor model (Schrank et al., 2005). Exploratory factor analysis (EFA; principal axis factoring [PAF] with oblique/Promax rotation) has also been used to evaluate the test validity. EFA of the WJ III produced two factors within the 6-13 age range, six factors within the 9-13 age range, and five factors within a 14-19 age range (Dombrowski \& Watkins, 2013; Strickland, Watkins, \& Caterino, 2015a) - all in contrast to the original technical manual 9-factor CFA results. Both CFA and EFA revealed a robust manifestation of $g$ in the WJ III, with some divergence between cognitive subdomains as indicated by CFA and EFA (Dombrowski \& Watkins, 2013; Strickland et al., 2015a).

While the perception of the Cattell-Horn-Carroll theory of cognitive abilities on which the WJ III is based considers the $g$ factor to reside at the apex of a hierarchy comprised of cognitive subdomains measured by individual subtests (the so-called "higher-order" model (Schrank et al., 2005), recent scholarship has argued that Carroll's intelligence theories are best understood to view the $g$ factor as separate from the cognitive subdomains, more consistent with a "bi-factor" model (Beaujean, 2015). Under this bi-factor model, each subtest score loads directly onto $g$ and separately onto the cognitive subdomain the subtest is hypothesized to measure. In this way the broad cognitive subdomain abilities are not considered to mediate the relationships between the subtest scores and $g$. Recent analysis of 31 test batteries in 58 datasets with over 1.7 
million test takers has found consistently stronger support for the bi-factor model over the higher-order model (Cucina \& Byle, 2017). In this study we examine whether the factor structure of scores from the Batería III COG among children living in the Peruvian Amazon may load onto 1) the hypothetically-tested cognitive subdomains alone, 2) a general $g$-factor alone, 3 ) a higher-order model where the cognitive subdomains load onto the $g$-factor, or 4) a bi-factor model where the test scores load onto the cognitive domains and onto $g$, separately.

Finally, the Woodcock-Johnson Cognitive Battery was updated in 2014 (fourth edition; WJ IV COG) (Schrank, McGrew, \& Mather, 2014) and has, since then, been subjected to additional examination in several groups of school aged children (Dombrowski, McGill, \& Canivez, 2017, 2018). As with the WJ III COG, exploratory factor analysis of the WJ IV COG revealed robust manifestation of the g-factor, which exceeded the variance attributed to the individual cognitive domain factors.

\section{Present study}

The broad objective of this study was to evaluate the structural validity of scores from the Batería III COG among Peruvian children living in the Amazon region in order to ensure that, in this population, this measure assesses the cognitive abilities that it purports to. The study's aim was, specifically, to use best practice factor analytic criteria to investigate the structure of scores from the Batería III COG in children aged 5 to 12 living in the southeast of Peru to determine whether the structure of scores matches that previously reported in other samples (e.g., Dombrowski, 2013; Strickland, Watkins, \& Caterino, 2015b; G.E. Taub \& McGrew, 2004; Gordon E. Taub \& McGrew, 2014). A brief-scale subset of the full battery was administered: ten tests contributing to six 
subscales that should yield a general intellectual ability $(g)$ and four cognitive subdomains (Verbal Comprehension via subtests 1a-1d; Working Memory via subtests 7 and 9; Processing Speed via subtests 6 part 1 and part 2 and test 20; and Fluid Reasoning via subtest 5).

Following the results of previous validation tests of the WJ III COG and current intelligence testing theory (e.g. Cucina \& Byle, 2017), we hypothesized that a bi-factor model would best represent the data, including one factor for $g$ and four separate factors for the tested cognitive domains. We anticipated that a $g$ factor would account for the majority of the variance, as has been previously found in the WJ III (Dombrowski \& Watkins, 2013; McGill \& Busse, 2015). As recommended by Jeanrie and Bertrand (1999), both statistical procedures and complementary systematic judgments were used to evaluate the appropriateness of the Batería III COG items in the Peruvian Amazon context.

\section{Methods}

\section{Participants}

Participants in this study are members of the Amarakaeri Cohort Study, which enrolled 1,221 households with at least one woman of childbearing age (aged 15-49) across 23 communities $(N=4,083)$ surrounding the Amarakaeri Communal Reserve, a large protected area in Madre de Dios, to study the impact of resource extraction on human and environmental health. Four communities were classified as urban $(\geq 100$ households) and 19 as rural ( $<100$ households) following the Peruvian National Census designations (Intituto Nacional de Estadistica e Informatica, n.d.). Furthermore, 11 of 19 
rural communities were classified as native, or ethnically indigenous (Native Federation of the Madre de Dios River and Tributaries, 2014), where inhabitants typically speak both Spanish and an indigenous tongue. Native languages included Yine, Harakbut, and Machiguenga. Baseline data was collected from 458 of 667 nuclear families between January and April 2016 (i.e., families consisting of a women of child-bearing age, their spouse/partner, and a child under 12; families were randomly selected). 212 children across 14 communities were eligible a priori (aged 5-12 years) for cognitive assessment. Cognitive data were collected from 164 children (57.2\% female) aged 5-12 years (Mean age $=8.0, \mathrm{SD}=2.0$ ), who represented $77 \%$ of those eligible. 28 children were from indigenous communities (17.1\% of the analytic sample), of whom 20 (71.4\%) spoke Spanish as a second language. All other children spoke Spanish as a first language. Spanish is learned at home (orally) and at school (both oral and written) while native languages are learned primarily at home. Literacy was not directly assessed. Informed consent was obtained from parents for each child, with, in addition, children aged 9 and above giving written consent and children below age 9 giving verbal assent. Approval to conduct research on human subjects was obtained through the Universidad Peruana Cayetano-Heredia Comité Institucional de Ética para Humanos (SIDISI 63056) and the Regional Health Directorate of Madre de Dios. Details on assessed communities' names and locations are available through the corresponding authors.

\section{Procedure}

The Batería III COG was administered by trained research staff using standard protocols described in the WJM manual (McGrew \& Woodcock, 2001). Children were tested at home between January and April 2016. 
The Batería III COG yields a GIA score using either the standard scale (scalelevel tests 1-10), the extended scale (scale-level tests 11-20), or the brief scale (described below). Due to time and resource constraints in assessment, we administered a subset of the full battery which yields the GIA score and, additionally, provides estimates of cognitive abilities in domains important to clinicians, parents, and teachers: Verbal Comprehension, Working Memory, Processing Speed, and Fluid Reasoning. Table 1 describes the administered tests using details from Taub \& McGrew (2014). A fuller description of the tests administered may be found in the Supplemental Materials (Table S1).

The composition of tests contributing to the cognitive ability subdomains in this study include:

- Verbal comprehension: tests $1 \mathrm{a}, 1 \mathrm{~b}, 1 \mathrm{c}$, and 1d (Verbal Comprehension).

- Working memory: test 7 (Numbers Reversed) and test 9 (Auditory Working Memory).

- Processing speed: test 6 (Visual Matching, part 1 and part 2) and test 20 (Pair Cancellation).

- Fluid Reasoning: test 5 (Concept Formation).

\section{Data management and analysis}

Analyses followed two steps. First, as a preliminary analysis, EFA tests were run on test items grouped within each measured cognitive domain (Verbal Comprehension, Working Memory, Processing Speed, and Fluid Reasoning) using the items that comprised the tests contributing to those domains to check for and ensure 
unidimensionality of the cognitive domains. When a single factor was identified for each domain, item-level scores that did not load onto the unidimensional factors were removed from further analysis. Scale-level total scores were recalculated for each participant using the remaining item-level scores. Second, in the main analysis, higher-model CFA tests were run to evaluate latent factors at the scale-level for four models: (a) a 10-subscaletest 4-correlated-factors model suggested by the four cognitive domains identified in the scale development and validation research, (b) a 10-subscale-test, 1-factor model suggested by the predominance of $g$ in WJ III tests, (c) a 10-subscale-test, higher-order model with four cognitive domains loading onto a single higher-order GIA, or $g$, factor, and (d) a 10-subscale-test, bi-factor model including three cognitive domains and, separately, the one $g$-factor.

Missingness of item-level data was examined and normality of the scale-level data was assessed before each analytic step, respectively. Basic descriptive statistics on the item-level data are provided in the results. Item-level correlation matrices, additional descriptive statistics, and findings from EFA and CFA not reported are available through the corresponding author. EFA and CFA were conducted using current best practices (Henson \& Roberts, 2006; Kline, 2005).

\section{EFA criteria.}

Common factor analysis was selected over principal components analysis (PCA) to better identify latent factor structures (Fabrigar, Wegener, MacCallum, \& Straham, 1999). The goal of EFA was to ensure unidimensionality of cognitive domain factors prior to the main CFA analysis. Criteria for determining adequacy of the unitary factor was established a priori: pattern coefficients $\geq 0.30$ were considered salient (Stevens, 
2009) and factor structures were considered adequate for interpretation if the factor met the following criteria: (a) $\geq$ four items with salient pattern coefficients, (b) internal consistency $\geq 0.70$, and (c) a theoretically meaningful pattern. Test items were grouped for analysis by cognitive subdomain. The total number of factors suggested by the itemlevel data was not examined.

\section{CFA criteria.}

CFAs (robust maximum likelihood estimation) were conducted on raw data (Kline, 2005) using Mplus Version 8 (Muthén \& Muthén, 2017). Omnibus fit was evaluated based on multiple criteria (Bollen \& Long, 1993). The comparative fit index (CFI) and Tucker-Lewis Index (TLI), with values $\geq 0.95$; the root mean square error of approximation (RMSEA) with values $\leq 0.06$; and the standardized root mean square residual (SRMR) with values $\leq 0.05$ were considered indicative of good fit (Kline, 2005). Akaike Information Criterion (AIC; Akaike, 1987) values were also examined. The Satorra-Bentler scaled $\chi^{2}$ was used for comparison purposes but was not interpreted directly because of a high likelihood of error (Lei \& Wu, 2007).

\section{Results}

\section{Preliminary analysis (Descriptives and EFA)}

No cases were missing scale-level data. One case was missing item-level data for subtests 6 and 7 and was removed from EFAs and CFAs analyzing those tests. All scalelevel data for the administered tests were normally distributed, with the exception of two tests, Test $1 \mathrm{a}$ and Test $1 \mathrm{~b}$, that displayed slight platykurtosis and one test, Test 6 part 1 , 
that was leptokurtic and negatively skewed. The non-normality of Test 6 part 1 reflected the fact that $85 \%$ of the tested children received perfect scores on this test. All scale-level test scores were normal after adjustments were made for the results of the EFAs (described below), with the exception of Test 6 part 1, which remained leptokurtotic and slightly skewed. Table 2 presents descriptive information on the administered tests. Correlations on total scale-level tests scores were moderate to high (ranging from $r=.41$ to $r=.84)$, and all were significant $(p<.001)$.

The primary preliminary analysis was EFA at the cognitive domain level to ensure unidimensionality of the cognitive domains before the CFA. Scores met the assumptions for EFA. One-dimensional common factor analysis (PAF extraction) was conducted on scores from each test item in the 10 administered subscale-tests grouped into the four cognitive domains. A number of items in each test had zero variance. These items were removed, and subsequent analyses were run without them. The number of items removed and the final item numbers tested are listed in Table 3. Supplemental Table S2 lists the exact items removed from each test due to zero variance. Test 20, a processing speed test involving identifying and circling repeated patterns, was not subjected to the EFA preliminary analysis because it only contained a single item (i.e., the number of patterns identified within the testing time). Test 20 did, however, contribute to the CFA analyses.

One-factor solutions were supported for each tested cognitive domain following the criteria previously specified. For the Verbal Comprehension domain, the single factor accounted for $22.25 \%$ of the variance. For the Working Memory domain, the single factor accounted for $32.51 \%$ of the variance. For the Processing Speed domain, the 
correlation matrix under PAF extraction was not initially positive definite and PCA extraction was used instead. Subsequently, a one-factor solution was supported for the Processing Speed domain; the single factor accounted for $36.75 \%$ of the variance. For the Fluid Reasoning domain, the single factor accounted for $35.56 \%$ of the variance.

Items that did not load significantly onto the single factor $(<.30)$ were removed and subsequent analyses were run without them. Supplemental Table S2 lists the exact items removed from each test due to low factor loadings. Re-running the original EFAs with these items removed improved the percent of variance accounted for by the unitary factors. After the removal of poorly loading items: a single factor accounted for $30.64 \%$ of the total variance among test items contributing to the Verbal Comprehension domain; a single factor accounted for $39.62 \%$ of the total variance among test items contributing to the Working Memory domain; a single factor accounted for $44.66 \%$ of the total variance among test items contributing to the Processing Speed domain; and a single factor accounted for $36.43 \%$ of the total variance among test items contributing to the Fluid Reasoning domain. Pattern coefficients for the test item loadings onto the unitary cognitive domain factors are provided in Supplemental Table S3.

After the EFAs were completed, scale-level total scores for each test were recalculated using only the individual test items remaining after those with zero variance and those with poor factor loading had been removed. Higher order CFAs were then run on the resulting total scale-level test scores in the main analysis. 


\section{Main analysis (CFA)}

Assumptions of CFA were met and maximum likelihood extraction (robust method) was used (Kline, 2005). CFAs were conducted on scores for four models: (a) a 10-subscale-test, 4-correlated-factors model suggested by the four cognitive domains identified in the scale development and validation research, (b) a 10-subscale-test, 1factor model suggested by the predominance of $g$ in WJ III tests, (c) a 10-subscale-test, higher-order model with the four cognitive domains identified loading onto a higherorder GIA or $g$-factor, and (d) a 10-subscale-test, bi-factor model including three cognitive domains and a separate GIA $g$-factor. ${ }^{1}$ Figure 1 presents the four hypothesized models tested in this study.

\section{Model results.}

\section{(a) The 4-correlated-factors model.}

The 10-subscale-test, 4-correlated-factors model included four factors representing the cognitive domains of Verbal Comprehension, Working Memory, Processing Speed, and Fluid Reasoning. As there was only one indicator available for the Fluid Reasoning factor (the Concept Formation test, test 5), following recommended practice (Hayduk \& Littvay, 2012) this indicator's loading onto the Fluid Reasoning factor was fixed to 1 and its error term fixed in relation to its reliability. The error term was fixed to " $a$," according to the formula $a=\operatorname{var}($ test 5$) *(1-r h o)$, where var(test 5) represents the variance of test 5 and rho its reliability as reported in the Woodcock

\footnotetext{
${ }^{1}$ Although the Fluid Reasoning test was included in the bifactor model, it was not possible to specify a loading on both the $g$-factor and a single-indicator Fluid Reasoning factor without fixing the parameters the model is designed to estimate and compare. Thus, we did not include a specific Fluid Reasoning factor, leaving the single indicator of Fluid Reasoning to load only on the $g$-factor.
} 
Johnson III technical manual (reliability of test $5=0.94$ ) (Schrank, McGrew, \& Woodcock, 2001).

Estimation of parameters proceeded normally for the 10-subscale-test, 4correlated-factors model. Goodness-of-fit indices suggested good fit for the model (e.g., CFI $\geq 0.95 ;$ SRMR $\leq 0.05)$ and are reported in Table 4. Standardized parameter estimates of factor loadings ranged from .59 to .93 and were statistically significant, with $p$-values $<.001$ (Table 5, Panel A). The correlation between the four factors was high, ranging from .73 to .90 , with $p$-values $<.001$.

\section{(b) The 1-factor model (g).}

The 10-subscale-test, 1-factor model included only one factor, the GIA or $g$ factor. Estimation of parameters proceeded normally for this model. Goodness-of-fit indices suggested good model fit (e.g., CFI $\geq 0.95$; SRMR $\leq 0.05$ ) (Table 4). As the 1factor model $\left(\chi^{2}(d f=35)=102.970\right)$ was nested within the 4-correlated factors model $\left(\chi^{2}\right.$ $(d f=30)=45.358)$, it was possible to test the significance of model fit decline moving to the more parsimonious, 1 -factor model using the Satorra-Bentler scaled $\chi^{2}$ difference test. The test was significant $\left(\Delta \chi^{2}(5)=44.471, p<.001\right)$, suggesting that the greater parsimony achieved in the 1 -factor model resulted in statistically significant decline in model fit relative to the more complex correlated-factors model. In contrast to most of the other fit statistics, the RMSEA for the 1-factor model suggested poor fit (.112). 


\section{(c) The higher-order model.}

The 10-subscale-test, higher-order model included four cognitive domain factors (representing Verbal Comprehension, Working Memory, Processing Speed, and Fluid Reasoning) loading onto a higher-order GIA or $g$-factor. As with the 4-correlated-factors model, there was only one indicator available for the Fluid Reasoning factor so recommend procedures were followed (i.e., the factor loading was fixed to one and error term fixed in relation to the indicator's reliability) (Hayduk \& Littvay, 2012).

Estimation of parameters proceeded normally for the 10-subscale-test, higherorder model. Goodness-of-fit indices suggested good fit for this model (e.g., CFI $\geq 0.95$; SRMR $\leq 0.05)$. As the higher-order model $\left(\chi^{2}(d f=32)=61.792\right)$ was nested within the 4correlated factors model $\left(\chi^{2}(d f=30)=45.358\right)$, it was possible to test the significance of model fit decline moving to the more parsimonious, higher-order model using the Satorra-Bentler scaled $\chi^{2}$ difference test. The test was significant $\left(\Delta \chi^{2}(2)=16.434, p<\right.$ $.001)$, suggesting that the greater parsimony achieved in the higher-order model resulted in statistically significant decline in model fit relative to the more complex correlatedfactors model. In the higher-order model, all indicators loaded significantly on the cognitive domain factors (standardized estimates between .60 and .95 , all $p$-values <.001) and the cognitive domain factors loaded strongly on the GIA $g$-factor (estimates between .84 and .98).

\section{(d) The bi-factor model.}

The 10-subscale-test, bi-factor model included the cognitive domains of Verbal Comprehension, Working Memory, and Processing Speed, and, separately, the one GIA 
or $g$-factor. Estimation of parameters for this model as initially specified did not converge. This was because the bi-factor model had two Heywood cases, where the estimated variances for the subscale tests were negative (Test $1 \mathrm{~d}$ and Test 6 Part 2). To correct this, the model was respecified, with the variances for Test $1 \mathrm{~d}$ and Test 6 Part 2 set to zero. This allowed for a model for which the estimation converged and otherwise proceeded normally. Goodness-of-fit indices suggested good fit for the 10-subscale-test, bi-factor model with three cognitive domains and one GIA, or $g$-factor (e.g., CFI $\geq 0.95$; SRMR $\leq 0.05)$. These statistics, reported in Table 4, suggested superior model fit to the 1-factor model, marginally superior fit to the higher-order model, and marginally inferior fit to the 4-correlated-factors model, although the differences between all models were minor.

All 10 subscale tests loaded strongly onto the GIA factor in the bi-factor model. Factor loading estimates for each test in this model are reported in Table 5 (Panel B). All tests generally loaded highly (from .74 to .88 ) save one test of processing speed, Test 6 Part 1 (standardized estimate $=.52)$. Individual subscale tests generally had low to moderate loadings on the unique cognitive subdomain factors (from .08 to .56); each loading on the $g$-factor was at least .27 higher than the corresponding loading on the group factor.

\section{Discussion}

This validation study of the Batería III COG for use among children living in the Peruvian Amazon used contemporary best-practice factor analytic techniques to examine the structure of scores yielded by 10 subscale tests of the Batería III COG. In this context, the scores supported both a correlated-factors (comprised of factors representing the 
unique cognitive domains of Verbal Comprehension, Working Memory, Processing Speed, and Fluid Reasoning) and a bi-factor model (comprised of factors representing the unique cognitive domains of Verbal Comprehension, Working Memory, and Processing Speed and a separate GIA $g$-factor). In the bi-factor model all administered subscales loaded highly onto the GIA factor and weakly onto factors hypothesized to represent the cognitive domains, pointing to the GIA factor as the primary source of commonality among the tests.

\section{Assessment implications}

Our results hold several implications for cognitive testing in the context of the Amazon region. First, our results suggest that scores from the Batería III COG may be useful for research and screening purposes among children aged 5 to 12 living in this region. Specifically, our findings support the use of the scores as a measure of general intellectual ability. To our knowledge, this is the first general intellectual ability measure of any kind to be validated on any children living in the Peruvian Amazon. If further research (e.g., studies of predictive validity) corroborates these findings, this scale could be useful at the individual child or community level. At the child level, such a measure can be used in schools to identify children with subtle learning disabilities, as indicated by large differences between general intellectual ability and test scores within a particular domain (e.g., math, reading). At the community level, such a measure can be used to identify communities in need of additional resources or intervention to improve child development outcomes, as indicated by large differences in average trends in children intellectual ability among demographically similar communities.

Second, based on the low factor loadings of the administered subscales onto the 
factors representing the narrow cognitive domains of Verbal Comprehension, Working Memory, and Processing Speed in the bi-factor model, our findings suggest caution in the use of the Batería III COG as a selective measure of a child's ability in these hypothesized domains, at least in the Peruvian Amazon. The good fit of the 4-correlatedfactors model representing Verbal Comprehension, Working Memory, Processing Speed, and Fluid Reasoning does suggest that the Batería III measures these abilities as selective, separate latent constructs. However, the large correlations seen among the factors (between .89 and .91) also suggests that these factors are not in fact entirely distinct constructs (hence the emergence of the $g$-factor in the bi-factor model). When the $g$ factor is accounted for separately from the cognitive domains, as in the bi-factor model, very little shared variance is left to be accounted for by the latent cognitive domain factors. This was particularly true for the Fluid Reasoning and Verbal Comprehension factors, which had test loading pattern coefficients of around .10 in the bi-factor model. In the predominance of the $g$ in the factor structure of scores from the Batería III COG among children in the Peruvian Amazon our results confirm previous findings regarding the Batería III's parent test, the WJ III COG. In school-aged normative and standardization samples (Dombrowski, 2013; Dombrowski \& Watkins, 2013; McGill \& Busse, 2015) as well as in students referred for special education services (Strickland et al., 2015a), $g$ has been found to dominate the facture structure of scores from the WJ III COG, with the test producing, in many reports, "limited predictive effects" beyond $g$ (McGill \& Busse, 2015, p. 353). The same finding appears to hold true in the revised WJIV (Dombrowski et al., 2017, 2018). In this sense our findings hold implications for cognitive testing and cognitive theory outside of the specific context of the Amazon 
region: our results add further evidence to the contention that interpretation of the WJ III COG should potentially be restricted to the $g$-factor. Further assessment of the Batería III COG will be needed, in studies with larger sample sizes, to determine whether it provides the best measurement of narrow hypothesized cognitive abilities over and above general intellectual ability, both in the specific context of the Peruvian Amazon and elsewhere around the world.

\section{Strengths and Limitations}

This study has several strengths. It is one of the first studies to have evaluated the use of cognitive tests in the Amazon region, and it is the first to have evaluated the Batería III COG in Peru. Critically, it includes children from a number of separate communities, including both those considered as rural ( $<100$ homes) and urban $(>100$ homes) and those considered as indigenous and non-indigenous. In this way, the study reflects, in part, the diversity and complexity of the region.

There are also limitations to this study. First, we did not administer the full 10 subscales of the standard scale of the Batería III COG nor any of the 10 subscales of the extended scale (in sum we administered 6 subscales of the standard scale, which yielded 10 subtest scores). Doing so would have allowed for greater examination of the Batería III COG's validity as a measure of the multiple cognitive domains that the full battery is theorized to assess. Having additional measures of Working Memory and Fluid Reasoning would also have allowed us to better match best practices for modeling latent variables, which posit an ideal minimum to be three indicators for each latent variable. Relatedly, we decomposed the Verbal Comprehension test into its four subtests to improve modeling verbal comprehension as a broad latent factor with narrower 
constituent abilities. While not commonly done within tests of the Woodcock Johnson scales, we found that doing so tended to improve model fit, as may result from item parceling (Matsunaga, 2008). Relatedly, while the Woodcock Johnson III, upon which the Bateria III is based, has revealed acceptable cross-age invariance in the pattern of tests scores across a wide span of ages (e.g., 6 to 90+ years) (G.E. Taub \& McGrew, 2004), we were underpowered to test cross-age invariance in this novel population. Second, the children included in this study may have experienced exposure to malnutrition, enteric infections, or neurotoxic metal mixtures owing to gold mining operations in the region. While this reflects a larger trend within the Peruvian Amazon and across rural areas in developing countries, it may limit the generalizability of our results to communities that do not routinely risk such exposures. Moreover, our rural Amazonian sample may not be representative of most children in Peru, who tend to live in more urban areas where access to health, nutrition, and education resources are generally greater. Potential differences in community-level literacy rates, child experiences in test-taking, and comfort in Spanish-language evaluations were not evaluated. Relatedly, while our study included children from indigenous communities, they represented only a portion of our sample (17.5\%), and further studies are warranted to validate these tests as an ideal measure of cognitive development in primarily indigenous communities. Finally, our sample size was small by the standards of CFA best practices, and we may have been underpowered to detect subtle effects (Wolf, Harrington, Clark, \& Miller, 2013). However, this sample was large by the standards of cognitive-development studies undertaken in isolated, rural communities in developing 
countries (e.g., Betancourt, Tapia, \& Méndez, 2015) and, further, exceeded the minimum requirements for CFAs with high predicted factor loadings (e.g., >.80) (Wolf et al., 2013).

\section{Future directions}

This study represents a crucial first step in evaluating the validity of the Batería III COG with children living in the Amazon region. Internal consistency and structural validity were evaluated, but research on criterion-related validity, inter-rater reliability, stability, and differential item functioning (DIF) is warranted. It will be important for future researchers to examine the Batería III COG tests with datasets that include both highly-urban (e.g., from large cities) and rural or small town-dwelling Peruvian children so that DIF can be evaluated directly (Hambleton, Yu, \& Slater, 1999). Further efforts to examine the use of the Batería III COG in this context could also take efforts to include scales that were not administered in this study. 


\section{References}

Akaike, H. (1987). Factor analysis and AIC. Psychometrika, 52(3), 317-332. https://doi.org/10.1007/BF02294359

Ashe, K. (2012). Elevated mercury concentrations in humans of Madre de Dios, Peru. PloS One, 7(3), e33305. https://doi.org/10.1371/journal.pone.0033305

Beaujean, A. A. (2015). John Carroll's views on intelligence: Bi-factor vs. higher-order models. Journal of Intelligence, 3(4), 121-136. https://doi.org/10.3390/jintelligence3040121

Betancourt, Ó., Tapia, M., \& Méndez, I. (2015). Decline of general intelligence in children exposed to manganese from mining contamination in Puyango river basin, Southern Ecuador. EcoHealth, 12(3), 453-460. https://doi.org/10.1007/s10393-015-1027-2

Blumen, S. (2016). New trends on intellectual assessment in Peru. International Journal of School \& Educational Psychology, 4(4), 254-261. https://doi.org/10.1080/21683603.2016.1166744

Bollen, K. A., \& Long, J. S. (1993). Testing structural equation models. SAGE.

Cerron-Palomino, R. (2009). Language policy in Peru: A historical overview. International Journal of the Sociology of Language, 1989(77), 11-34. https://doi.org/10.1515/ijsl.1989.77.11

Cucina, J., \& Byle, K. (2017). The bifactor model fits better than the higher-order model in more than $90 \%$ of comparisons for mental abilities test batteries. Journal of Intelligence, 5(3), 27. https://doi.org/10.3390/jintelligence5030027 
Diringer, S. E., Feingold, B. J., Ortiz, E. J., Gallis, J. A., Araújo-Flores, J. M., Berky, A., ... Hsu-Kim, H. (2015). River transport of mercury from artisanal and small-scale gold mining and risks for dietary mercury exposure in Madre de Dios, Peru.

Environmental Science: Processes \& Impacts, 17(2), 478-487. https://doi.org/10.1039/C4EM00567H

Dombrowski, S. C. (2013). Investigating the structure of the WJ-III Cognitive at school age. School Psychology Quarterly: The Official Journal of the Division of School Psychology, American Psychological Association, 28(2), 154-169. https://doi.org/10.1037/spq0000010

Dombrowski, S. C., McGill, R. J., \& Canivez, G. L. (2017). Exploratory and hierarchical factor analysis of the WJ-IV Cognitive at school age. Psychological Assessment, 29(4), 394-407. https://doi.org/10.1037/pas0000350

Dombrowski, S. C., McGill, R. J., \& Canivez, G. L. (2018). Hierarchical exploratory factor analyses of the Woodcock-Johnson IV Full Test Battery: Implications for CHC application in school psychology. School Psychology Quarterly: The Official Journal of the Division of School Psychology, American Psychological Association, 33(2), 235-250. https://doi.org/10.1037/spq0000221

Dombrowski, S. C., \& Watkins, M. W. (2013). Exploratory and higher order factor analysis of the WJ-III full test battery: A school-aged analysis. Psychological Assessment, 25(2), 442-455. https://doi.org/10.1037/a0031335

Fabrigar, L. R., Wegener, D. T., MacCallum, R. C., \& Straham, E. J. (1999). Evaluating the use of exploratory factor analysis in psychological research. Psychological Methods, 4, 272-299. 
Feingold, B. J., \& Mulanovic, G. S. (2014). Land use, household vulnerability and dual disease burden among children living in the Peruvian Amazon. In Abstracts of the 2014 Conference of the International Society of Environmental Epidemiology (ISEE). Research Triangle Park, NC: Environmental Health Perspectives.

Grantham-McGregor, S., Cheung, Y. B., Cueto, S., Glewwe, P., Richter, L., \& Strupp, B. (2007). Developmental potential in the first 5 years for children in developing countries. The Lancet, 369(9555), 60-70. https://doi.org/10.1016/S01406736(07)60032-4

Hall, G. (2005). Indigenous Peoples, Poverty and Human Development in Latin America. New York, NY: Springer.

Hambleton, R. K., Yu, J., \& Slater, S. C. (1999). Field test of the ITC guidelines for adapting educational and psychological tests. European Journal of Psychological Assessment, 15(3), 270-276. https://doi.org/10.1027//1015-5759.15.3.270

Hayduk, L. A., \& Littvay, L. (2012). Should researchers use single indicators, best indicators, or multiple indicators in structural equation models? BMC Medical Research Methodology, 12(1), 159. https://doi.org/10.1186/1471-2288-12-159

Henson, R. K., \& Roberts, J. K. (2006). Use of exploratory factor analysis in published research: Common errors and some comment on improved practice. Educational and Psychological Measurement, 66(3), 393-416. https://doi.org/10.1177/0013164405282485

Intituto Nacional de Estadistica e Informatica. (n.d.). Variables Contextuales. Retrieved from 
https://www.inei.gob.pe/media/MenuRecursivo/publicaciones_digitales/Est/Lib00 14/varicont.htm.

Jeanrie, C., \& Bertrand, R. (1999). Translating tests with the International Test Commission's guidelines: Keeping validity in mind. European Journal of Psychological Assessment, 15(3), 277-283. https://doi.org/10.1027//10155759.15 .3 .277

Kline, R. B. (2005). Principles and practice of structural equation modeling. New York, NY: Guilford Press.

Lei, P.-W., \& Wu, Q. (2007). Introduction to structural equation modeling: Issues and practical considerations. Educational Measurement: Issues and Practice, 26(3), 33-43. https://doi.org/10.1111/j.1745-3992.2007.00099.x

Mather, N., Woodcock, R. W., Wolfson, L., McGrew, K. S., Schrank, F. A., Ruef, M. L., ... Riverside Publishing Company. (2008). Batería III Woodcock-Muñoz. Itasca, IL: Riverside Pub.

McGill, R. J., \& Busse, R. T. (2015). Incremental validity of the WJ III COG: Limited predictive effects beyond the GIA-E. School Psychology Quarterly: The Official Journal of the Division of School Psychology, American Psychological Association, 30(3), 353-365. https://doi.org/10.1037/spq0000094

McGrew, K. S., \& Woodcock, R. W. (2001). Technical manual: Woodcock-Johnson III. Itasca, IL: Riverside.

Muthén, L. K., \& Muthén, B. O. (2017). MPlus user's guide (8th ed.). Los Angeles, CA: Muthén \& Muthén. 
Myers, N., Mittermeier, R. A., Mittermeier, C. G., da Fonseca, G. A., \& Kent, J. (2000). Biodiversity hotspots for conservation priorities. Nature, 403(6772), 853-858. https://doi.org/10.1038/35002501

Native Federation of the Madre de Dios River and Tributaries. (2014). Native Federation of the Madre de Dios River and Tributaries. Retrieved April 12, 2018, from http://www.fenamad.org.pe/

Oliveira, P. J. C., Asner, G. P., Knapp, D. E., Almeyda, A., Galván-Gildemeister, R., Keene, S., ... Smith, R. C. (2007). Land-use allocation protects the Peruvian Amazon. Science, 317(5842), 1233-1236. https://doi.org/10.1126/science.1146324

Perz, S., Brilhante, S., Brown, F., Caldas, M., Ikeda, S., Mendoza, E., ... Walker, R. (2008). Road building, land use and climate change: Prospects for environmental governance in the Amazon. Philosophical Transactions of the Royal Society B: Biological Sciences, 363(1498), 1889-1895. https://doi.org/10.1098/rstb.2007.0017

Reynolds, C. R., \& Suzuki, L. (2013). Bias in psychological assessment: An empirical review and recommendations. Handbook of Psychology, Volume 10: Assessment Psychology. Retrieved from https://nyuscholars.nyu.edu/en/publications/bias-inpsychological-assessment-an-empirical-review-and-recommen

Schrank, F. A., McGrew, K. S., Mary L. Ruef, Alvarado, C. G., Munoz-Sandoval, A. F., \& Woodcock, R. W. (2005). Overview and technical supplement (Batería III Woodcock-Muñoz Assessment Service Bulletin No. 1). Rolling Meadows, IL: Riverside Publishing. 
Schrank, F. A., McGrew, K. S., \& Mather, N. (2014). Woodcock-Johnson IV. Rolling Meadows, IL: Riverside Publishing.

Schrank, F. A., McGrew, K. S., \& Woodcock, R. W. (2001). Technical Abstract. Itasca, IL: Riverside Publishing.

Stevens, J. (2009). Applied Multivariate Statistics for the Social Sciences. Abingdon, UK: Routledge.

Strickland, T., Watkins, M. W., \& Caterino, L. C. (2015a). Structure of the WoodcockJohnson III cognitive tests in a referral sample of elementary school students. Psychological Assessment, 27(2), 689-697. https://doi.org/10.1037/pas0000052

Strickland, T., Watkins, M. W., \& Caterino, L. C. (2015b). Structure of the WoodcockJohnson III cognitive tests in a referral sample of elementary school students. Psychological Assessment, 27(2), 689-697. https://doi.org/10.1037/pas0000052

Taub, G.E., \& McGrew, K. S. (2004). A confirmatory factor analysis of Cattell-HornCarroll theory and cross-age invariance of the Woodcock-Johnson Tests of Cognitive Abilities III. School Psychology Quarterly, 19, 72-87.

Taub, Gordon E., \& McGrew, K. S. (2014). The Woodcock-Johnson Tests of Cognitive Abilities III's cognitive performance model: Empirical support for intermediate factors within CHC Theory. Journal of Psychoeducational Assessment, 32(3), 187-201. https://doi.org/10.1177/0734282913504808

The World Bank. (2018). Peru: Overview. Retrieved March 7, 2018, from http://www.worldbank.org/en/country/peru/overview 
United Nations. (2017). World economic situation and prospects 2018. Retrieved from https://www.un.org/development/desa/publications/world-economic-situationand-prospects-wesp-2017.html

Walker, S. P., Wachs, T. D., Gardner, J. M., Lozoff, B., Wasserman, G. A., Pollitt, E., \& Carter, J. A. (2007). Child development: Risk factors for adverse outcomes in developing countries. The Lancet, 369(9556), 145-157. https://doi.org/10.1016/S0140-6736(07)60076-2

Weinhouse, C., Ortiz, E. J., Berky, A. J., Bullins, P., Hare-Grogg, J., Rogers, L., ... Pan, W. K. (2017). Hair mercury level is associated with anemia and micronutrient status in children living near artisanal and small-scale gold mining in the Peruvian Amazon. The American Journal of Tropical Medicine and Hygiene, 97(6), 18861897. https://doi.org/10.4269/ajtmh.17-0269

Wolf, E. J., Harrington, K. M., Clark, S. L., \& Miller, M. W. (2013). Sample size requirements for Structural Equation Models: An evaluation of power, bias, and solution propriety. Educational and Psychological Measurement, 76(6), 913-934. https://doi.org/10.1177/0013164413495237

Woodcock, R. W., McGrew, K. S., \& Mather, N. (2001). Woodcock-Johnson III. Itasca, IL: Riverside Publishing.

Wyatt, L., Ortiz, E. J., Feingold, B., Berky, A., Diringer, S., Morales, A. M., ... Pan, W. (2017). Spatial, temporal, and dietary variables associated with elevated mercury exposure in Peruvian riverine communities upstream and downstream of artisanal and small-scale gold mining. International Journal of Environmental Research and Public Health, 14(12), 1582. https://doi.org/10.3390/ijerph14121582 


\section{Tables \& Figures}

Table 1. Administered subscales and contributing tests of the Batería III COG.

\begin{tabular}{|c|c|}
\hline Test number & Subscale description \\
\hline Test $1 \mathrm{a}, \mathrm{b}, \mathrm{c}, \mathrm{d}$ & $\begin{array}{l}\text { Verbal Comprehension (Comprensión verbal) - four subtests measure } \\
\text { aspects of language development in Spanish, such as knowledge of } \\
\text { vocabulary or the ability to reason using lexical (word) knowledge, to } \\
\text { create a measure of acquired verbal knowledge. }\end{array}$ \\
\hline Test 5 & $\begin{array}{l}\text { Concept Formation (Formación de conceptos) - a fluid reasoning } \\
\text { subtest that involves inductive reasoning about categorical relationships } \\
\text { among orally-relayed words to create a measure of fluid logic, inference, } \\
\text { rule-based categorization, and rule switching ability. }\end{array}$ \\
\hline $\begin{array}{l}\text { Test } 6 \text { part } 1 \text { and } \\
\text { part } 2\end{array}$ & $\begin{array}{l}\text { Visual Matching (Pareo Visual) - two subtests that involve rapidly } \\
\text { identifying two identical symbols (part 1) or numbers (part 2) within a line } \\
\text { of numbers create a measure of speed of mental processing during } \\
\text { relatively simple cognitive tasks requiring sustained attention and } \\
\text { concentration. }\end{array}$ \\
\hline Test 7 & $\begin{array}{l}\text { Numbers Reversed (Inversión de Númerous) - a working memory } \\
\text { subtest requiring the retention and mental manipulation of a sequence of } \\
\text { numbers to create a measure of short-term working memory ability, } \\
\text { particularly the ability to consciously store, maintain, and use information } \\
\text { presented within a few seconds. }\end{array}$ \\
\hline Test 9 & $\begin{array}{l}\text { Auditory Working Memory (Memoria de Trabajo Auditiva) - a subtest } \\
\text { requiring the recoding of acoustic, verbalizable stimuli held in immediate } \\
\text { awareness to create a measure of short-term working memory ability, } \\
\text { particularly the ability to consciously store, maintain, and use auditory } \\
\text { information within a few seconds. }\end{array}$ \\
\hline Test 20 & $\begin{array}{l}\text { Pair Cancellation (Cancelación de Pares) - a subtest that involves } \\
\text { locating and marking a repeated pattern as quickly as possible to create a } \\
\text { measure of speed of mental processing during relatively simple cognitive } \\
\text { tasks requiring sustained attention and vigilance. }\end{array}$ \\
\hline
\end{tabular}


Table 2. Descriptive information on the administered Batería III COG subscales.

\begin{tabular}{lllrr}
\hline Test group & Test name & Range & Mean & SD \\
\hline Test 1 & Verbal Comprehension Test 1a & 0 to 8 & 3.88 & 2.06 \\
& Verbal Comprehension Test 1b & 0 to 7 & 1.99 & 1.95 \\
& Verbal Comprehension Test 1c & 0 to 11 & 5.96 & 3.28 \\
& Verbal Comprehension Test 1d & 0 to 10 & 4.55 & 2.69 \\
Test 5 & Concept Formation & 0 to 35 & 12.20 & 8.99 \\
Test 6 & Visual Matching part 1 & 4 to 18 & 20.85 & 3.44 \\
& Visual Matching part 2 & 0 to 34 & 19.50 & 10.41 \\
Test 7 & Numbers Reversed & 0 to 13 & 5.73 & 4.11 \\
Test 9 & Auditory Working Memory & 0 to 23 & 6.08 & 6.00 \\
Test 20 & Pair Cancellation & 0 to 67 & 32.00 & 16.69 \\
\hline
\end{tabular}


Table 3. Number of Batería III COG test items originally administered and subsequently omitted from or included in exploratory factor analyses, by cognitive subdomain.

\begin{tabular}{lccc}
\hline Cognitive Domain & $\begin{array}{l}\text { Total test items } \\
\text { administered }\end{array}$ & $\begin{array}{l}\text { Items omitted } \\
\text { because of zero } \\
\text { variance }\end{array}$ & $\begin{array}{l}\text { Final items } \\
\text { entered initially } \\
\text { in each EFA }\end{array}$ \\
\hline Verbal Comprehension & 73 & 21 & 52 \\
Processing Speed & 86 & 20 & 66 \\
Working Memory & 72 & 16 & 56 \\
Fluid Reasoning & 40 & 0 & 40 \\
\hline
\end{tabular}

Note. "Total test items administered" represents the total possible number of test items a child could have received were they to have passed discontinue criteria. 
Table 4. Model fit statistics for the 4-correlated-factors, 1-factor, higher-order, and bifactor models tested through confirmatory factor analysis $(\mathrm{N}=163)$.

\begin{tabular}{lcccccccc}
\hline Model & $\boldsymbol{\chi}^{2}$ & $\boldsymbol{d} \boldsymbol{f}$ & CFI & TLI & RMSEA & $\begin{array}{l}\text { RMSEA } \\
\text { 90\% CI }\end{array}$ & SRMR & AIC \\
\hline $\begin{array}{l}\text { 4-correlated } \\
\text { factors } \\
\text { model }\end{array}$ & $45.358 *$ & 30 & .988 & .982 & .056 & $.015-.088$ & .026 & 8361.729 \\
$\begin{array}{l}1 \text {-factor } \\
\text { model }\end{array}$ & $102.970 * * *$ & 35 & .946 & .931 & .109 & $.085-.134$ & .035 & 8409.964 \\
$\begin{array}{l}\text { Higher-order } \\
\text { model }\end{array}$ & $61.792 * *$ & 32 & .976 & .967 & .076 & $.047-.104$ & .028 & 8373.299 \\
$\begin{array}{l}\text { Bi-factor } \\
\text { model }\end{array}$ & $49.513 *$ & 29 & .984 & .975 & .066 & $.032-.097$ & .025 & 8369.336 \\
\hline
\end{tabular}

Notes. $* \mathrm{p}<.05, * * \mathrm{p}<.01, * * * \mathrm{p}<.001 . \mathrm{CI}=$ Confidence Interval. 
Table 5. Factor loading estimates (standardized pattern coefficients) for the 4-correlatedfactors model (A) and the bi-factor model (B).

A. Factor loadings (standardized parameter estimates) for the 4-correlated-factors model.

\begin{tabular}{ccccc}
\hline Factor & Test & $\begin{array}{c}\text { Loading } \\
\text { Estimate }\end{array}$ & S.E. & $p$-value \\
& T1a & .82 & .03 & $<.001$ \\
Verbal & T1b & .81 & .03 & $<.001$ \\
Comprehension & T1c & .81 & .03 & $<.001$ \\
Factor & T1d & .86 & .02 & $<.001$ \\
& & & & \\
\hline Working & T7 & .93 & .03 & $<.001$ \\
Memory Factor & T9 & .77 & .03 & $<.001$ \\
& & & & \\
\hline Processing & T6 part 1 & .59 & .04 & $<.001$ \\
Speed Factor & T6 part 2 & .94 & .02 & $<.001$ \\
& T20 & .90 & .02 & $<.001$ \\
\hline Fluid Reasoning & T5 & .97 & .003 & $<.001$ \\
Factor & & & & \\
\hline
\end{tabular}

B. Factor loadings (standardized parameter estimates) for the bi-factor model

\begin{tabular}{|c|c|c|c|c|}
\hline Factor & Test & $\begin{array}{l}\text { Loading } \\
\text { Estimate }\end{array}$ & S.E. & $p$-value \\
\hline \multirow{4}{*}{$\begin{array}{c}\text { Verbal } \\
\text { Comprehension } \\
\text { Factor }\end{array}$} & T1a & .08 & .05 & 134 \\
\hline & $\mathrm{T} 1 \mathrm{~b}$ & .10 & .06 & .076 \\
\hline & $\mathrm{T} 1 \mathrm{c}$ & .12 & .05 & .011 \\
\hline & T1d & .56 & .05 & $<.001$ \\
\hline \multirow{2}{*}{$\begin{array}{c}\text { Working } \\
\text { Memory Factor }\end{array}$} & $\mathrm{T} 7$ & .29 & .01 & $<.001$ \\
\hline & T9 & .31 & .11 & .007 \\
\hline \multirow{3}{*}{$\begin{array}{c}\text { Processing } \\
\text { Speed Factor }\end{array}$} & T6 part 1 & .29 & .05 & $<.001$ \\
\hline & T6 part 2 & .48 & .04 & $<.001$ \\
\hline & $\mathrm{T} 20$ & .21 & .06 & $<.001$ \\
\hline \multirow{4}{*}{$\begin{array}{c}\text { General } \\
\text { Intellectual } \\
\text { Ability Factor }\end{array}$} & T1a & .81 & .03 & $<.001$ \\
\hline & $\mathrm{T} 1 \mathrm{~b}$ & .79 & .03 & $<.001$ \\
\hline & T1c & .79 & .03 & $<.001$ \\
\hline & T1d & .83 & .04 & $<.001$ \\
\hline
\end{tabular}




$\begin{array}{cccc}\text { T7 } & .86 & .02 & <.001 \\ \text { T9 } & .74 & .04 & <.001 \\ \text { T6 part 1 } & .52 & .04 & <.001 \\ \text { T6 part 2 } & .88 & .02 & <.001 \\ \text { T20 } & .84 & .02 & <.001 \\ \text { T5 } & .82 & .03 & <.001\end{array}$


Figure 1. The four hypothesized models tested in this study.

(A) The 10-subscale-test, 4-correlated-factors model.

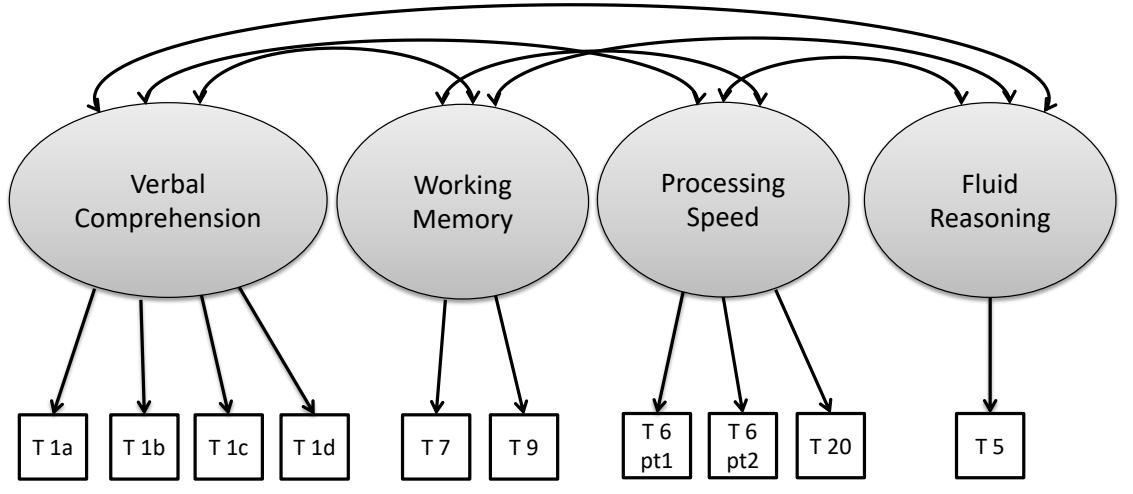

(B) The 10-subscale-test, 1-factor model.

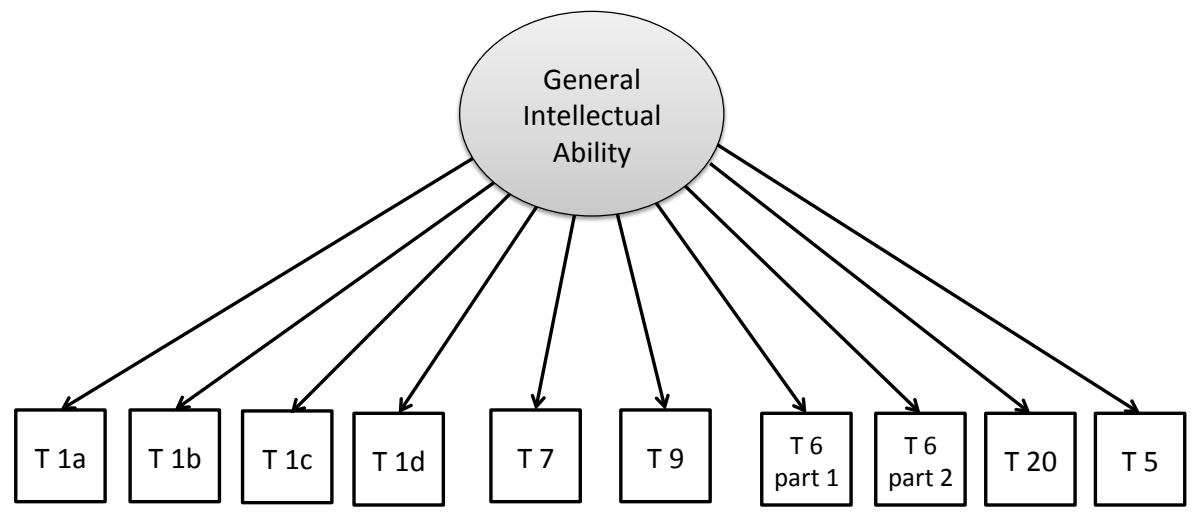

(C) The 10-subscale-test, higher-order model.

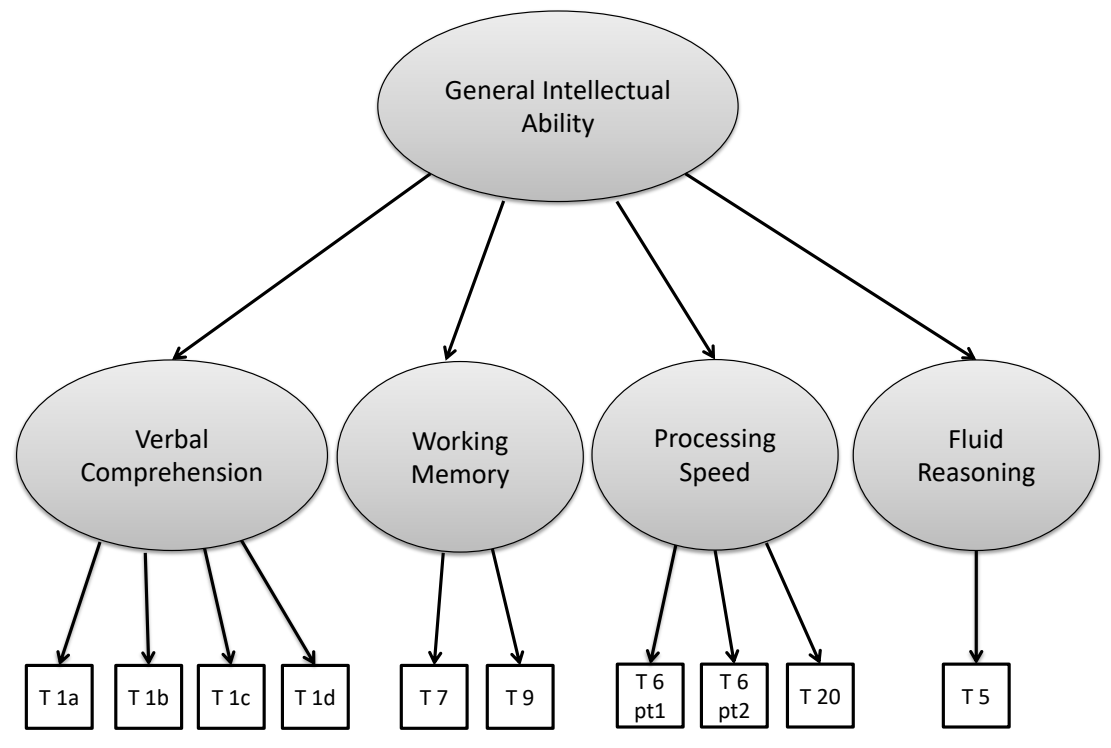


(D) The 10-subscale-test, bi-factor model.

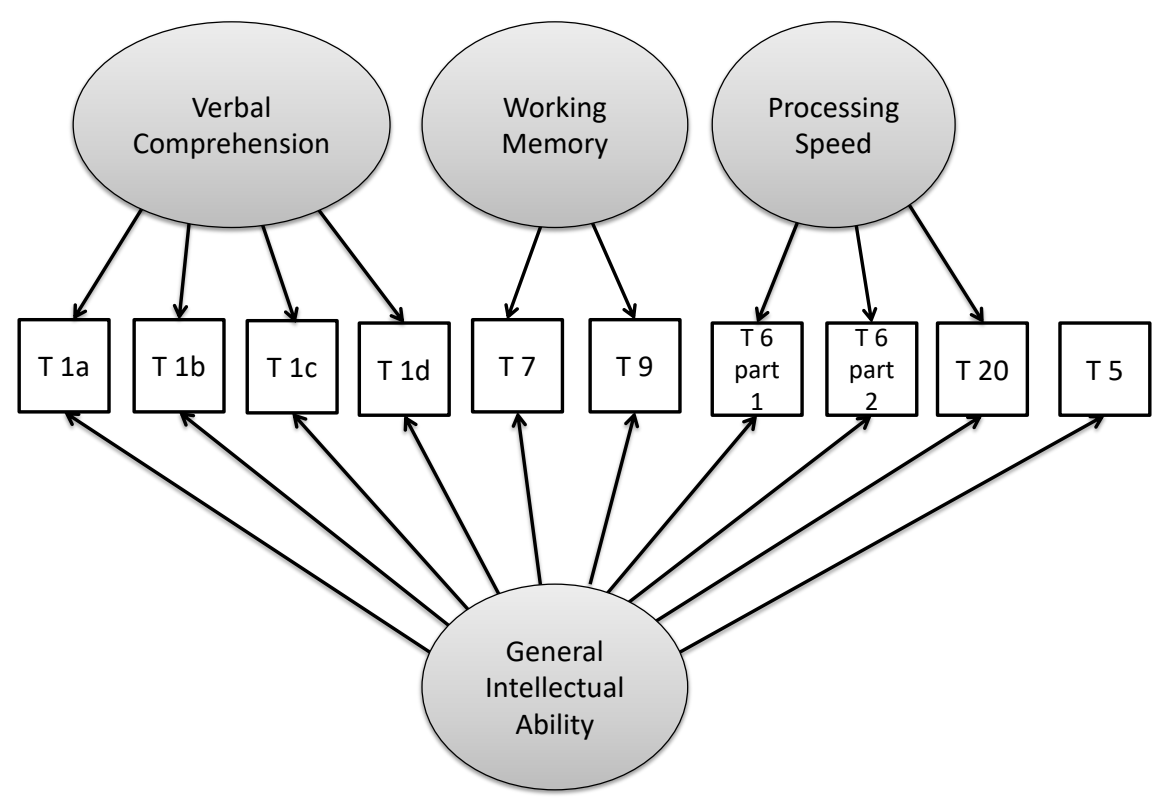

